\title{
ANALYSIS OF COMPUTER-MEDIATED COMMUNICATION: USING FORMAL CONCEPT ANALYSIS AS A VISUALIZING METHODOLOGY* ${ }^{\dagger}$
}

\author{
NORIKO HARA, PH.D. \\ Indiana University, Bloomington
}

\begin{abstract}
Computer-Mediated Communication (CMC) is used in different contexts such as business, non-profit organizations, and education and uses different tools such as computer conferencing, e-mail, and groupware. However, it is apparent that the field of CMC lacks established methodologies to analyze the phenomena. This article introduces the use of Formal Concept Analysis (FCA) as a methodology to visualize the data in CMC. FCA is based on a mathematical lattice theory and offers visual maps (graphs) with conceptual hierarchies. Combined with content analysis, FCA is proposed to be a potential method for the analysis of CMC. In this study, three categories (social, cognitive, and metacognitive) from Henri's (1992) model for CMC content analysis were applied to FCA after a previous study used a contentanalysis method based on Henri's model to convert the data from a computer conference. The purpose of this article is to provide an example of the application of FCA to CMC and to argue for its potential use for analyzing on-line discourse. Although this article specifically addresses issues related to analyzing data in CMC for education, the methodology is applicable to the analysis of CMC for different purposes.
\end{abstract}

\footnotetext{
*An earlier version of this article was presented at the annual meeting of the American Educational Research Association in New Orleans, April 24-28, 2000.

${ }^{\dagger}$ This article is based upon work supported in part by the STC program of the National Science Foundation under Agreement No. CHE-9876674.
} 


\section{INTRODUCTION}

The use of Computer-Mediated Communication (CMC) in education is becoming widespread (Bonk \& King, 1988; Colomb \& Simutis, 1996; Harasim, 1990, 1993; Kuehn, 1994). Computers have extended human intellectual processes (Harasim, 1990). Mason and Kaye (1990) promote the potential use of CMC for distance education. At the same time, however, they caution about the danger of "the prepackaging of knowledge" (p. 17) and claim the importance of examining the process of CMC. Harasim (1990) argues for investigating how on-line learning can contribute to learning. To answer these concerns, we need tools to examine the effectiveness of the use of CMC in education.

It is, however, unfortunate that there has been little exploration of methodologies that are effective in systematically analyzing phenomena in CMC (Romiszowski \& Mason, 1996). Romiszowski and Mason (1996) claim that the method most frequently used in research on CMC is surveying students and instructors, although evaluative case studies are also relatively popular. Survey studies and evaluative case studies tend to provide limited perspectives.

This present article proposes the use of Formal Concept Analysis (FCA) with a combination of content analysis as a tool to systematically analyze on-line dynamics (e.g., how the discussions change over time). This study was conducted to analyze on-line discussion in an applied educational psychology course at an American university during the spring of 1997. In order to apply FCA, two steps are necessary. The first step is to convert the raw data (student messages) into some categories, and the second step is to use these categories to apply FCA. Thus, this present study followed a previous study (Hara, Bonk \& Angeli, 2000) where content analysis was used to convert the original data into five categories as identified by Henri (1992). Henri's framework includes five dimensions: participative, interactive, social, cognitive, and metacognitive (see the Content Analysis section for details). In the present study, FCA is applied in order to analyze the dynamics in computer conferences, verify the findings from the previous study, and developing the analysis further.

The purposes of the present study were twofold: 1) to explore how FCA can help a researcher analyze data; and 2) to examine how the dynamics of on-line discussions may facilitate students' cognitive and metacognitive development throughout the semester. The study focused on one class as a whole learning environment, analyzing the data on a weekly basis rather than focusing on each message. In addition, individual student messages were separately analyzed week by week in light of metacognitive and social dimensions. The researcher was interested in the dynamics of the on-line discussion and how students' cognitive and metacognitive discourses were related to social cues (e.g., greetings or social expressions) occurring in this computer conference. For this reason, the first two categories of Henri's model (1992), participation and interaction, do not match the purposes of the study. The present study, therefore, analyzed the relationships 
among the three categories - social, cognitive, and metacognitive — using FCA as a methodology.

The researcher pursued the following research questions: how are two sets of three dimensions (cognitive and social; metacognitive and social) related to each other? How did each student reveal his/her social, cognitive, and metacognitive skills in the on-line conference?

\section{SIGNIFICANCE OF THE STUDY}

The major advantage of using FCA is its capacity to aid in visualizing data. This allows researchers to examine $\mathrm{CMC}$ from a different perspective: in the past, the majority of studies on the phenomena simply used quantitative methodology to analyze the data (Kuehn, 1994; Romiszowski \& Mason, 1996). Computer technology makes it easy to obtain statistical data, such as access times and students' participation (Harasim, 1987). However, since numerical data typically show only the number of messages and the number of posted words, it is difficult to grasp the actual phenomena. Thus, Kuehn (1994) asserts that more studies are needed to investigate the instructional uses of CMC.

Romiszowski and Mason (1996) note the small amount of qualitative research conducted in CMC, especially the lack of transcript analysis (or content analysis). Although there are some studies (e.g., Howell-Richardson \& Mellar, 1996; Newman, Johnson, Webb, \& Cochrane, 1997; Weedman, 1999) using content analysis for computer conferencing analysis, none of them ascertain a suitable method to analyze the data. For example, Howell-Richardson and Mellar (1996) state that few instruments for content or interaction analysis of CMC transcripts are available. Therefore, this present study describes the application of FCA to the analysis of CMC and shows how FCA can be a powerful methodology to analyze qualitative data in the study of CMC.

There are different potential uses of FCA in terms of the research on CMC. First, even though the example used in the present article specifically came from an educational setting, FCA can be applied to the analysis of CMC in different contexts, such as business. Kies, Williges, and Rosson (1998) discuss three research strategies for computer-supported cooperative work (CSCW): theorybased design, ethnographic methods, and controlled testing methods. In addition to these three research methods, FCA could be a research strategy to analyze the use of CSCW. For instance, Yates, Orlikowski, and Okamura (1999) analyze genres that appeared in on-line discussions featuring R\&D workers. The relationships among the genres could be investigated by using FCA. Yates et al. develop eight categories (i.e., response, solicitation, lost and found, meta-medium, apology, report, announcement, and recreational) under the genre of "purpose of messages." FCA could also reveal the relationships among three of the categories (response, report, and announcement) and examine how these are related in on-line discussions. 
Second, understanding how to facilitate on-line discussion is a crucial issue in this field. Perhaps FCA could be a tool to examine discussion facilitators' roles in on-line conferencing. Since FCA gives deeper insights of the dynamics of on-line discussions, designers or even facilitators themselves might be able to evaluate the effectiveness of on-line discourses. Therefore, this present article addresses FCA as a potential methodology for the analysis of CMC, because the application of FCA to content analysis examines the details of the phenomena in on-line discussions.

Furthermore, the connections between social, cognitive, and metacognitive skills have been speculated on, but not yet articulated. Henri (1992), who developed the original framework for the content analysis of this study, had raised but not resolved questions about the link between social and metacognitive dimensions. Schoenfeld (1999) discussed the separation of social and cognitive perspectives in education and called for an alliance between the two. FCA will serve as a tool to investigate the relationships of social/cognitive and social/ metacognitive dimensions in his article.

\section{CONTENT ANALYSIS}

Kuehn (1994) claims that content analysis is "one of the most promising areas for research" (p. 175). Content analysis for on-line discussion in educational settings has been used for different CMC research (Ahern, Peck, \& Laycock, 1992; Henri, 1992; Howell-Richardson \& Mellar, 1996; Mowrer, 1996; Newman et al., 1997). Ahern et al. (1992) apply content analysis for computer conferences that are controlled under three different conditions: formal question-asking, informal question-asking, and casual conversation. They investigate how college students' responses could change based on how the instructor asked questions differently under these conditions.

Howell-Richardson and Mellar (1996) use Speech Act Theory as their theoretical foundation and analyze the data by message length, distribution, message links, and interaction. Speech Act Theory is a theory based on the notion that what people say is consistent with what they do. The last category, interaction analysis, is where content analysis is used. Mowrer (1996) analyzes the discussion between students and the instructor but his analysis remains superficial. However, he does employ content analysis of general topics that students discussed during computer conferencing. Again, Henri (1992) provides a framework for content analysis that includes five dimensions of learning processes: participation, interaction, social, cognitive, and metacognitive. To evaluate students' critical thinking in on-line discussions, Newman et al. (1997) combined Henri's model with Garrison's theory of critical thinking.

There are different perspectives on content analysis that can be considered as objective or subjective. Groeben and Rustemeyer (1994) introduce two perspectives on content analysis: the first is an objective, systematic, and quantitative 
technique; the second is an intersubjective and qualitative technique. Although better criteria for content analysis are prerequisite in order to use FCA, a concrete method to analyze $\mathrm{CMC}$ is still under development. One of the obstacles is that the current method is considerably more subjective because it lacks clear criteria for content analysis. Incorporating observer-agreement technique overcomes this drawback of content analysis. Observer-agreement technique is having a second researcher categorize the data and then compare the frequency of each category between the first and second researchers. As a result, interrater reliability is calculated.

Although Howell-Richardson and Mellar (1996) criticize Henri's model for its subjectivity and ambiguousness of criteria applied to each dimension, the present researcher used Henri's framework (1992) to analyze the data. Even though Henri's framework requires improvement, his model supplies categories that the present researcher was interested in examining (both the cognitive and metacognitive dimensions) and clearer criteria than past studies on content analysis (Ahern et al., 1992; Howell-Richardson \& Mellar, 1996; Mowrer, 1996). To be more specific, Henri's model includes indicators for each category. For example, an indicator for elementary clarification is "asking a relevant question." Furthermore, Henri's ambiguous criteria were refined in the previous research project (see Hara et al., 2000) and the aggregate observer agreement was 74.6 percent, so this data-coding schema was considered reliable.

As previously mentioned, Henri's framework helps analyze participative, interactive, social, cognitive, and metacognitive dimensions of CMC. Among these categories, participation represents numerical data. Interaction depicts the relations of who responds to whose message(s). Social cues include social messages such as self-introduction and signs such as a smiley face mark (i.e., : - ) ). According to Henri, the researchers evaluated on-line discussions based on the existence of social cues in a particular message. If social cues exist, we checked yes for the social dimension (see Table 2 for an example). Although developing subcategories for social dimensions could be informative, it was beyond the scope of this study. However, another study (see Beatty, Bonk, \& Hara, 2001) related to this present research uses more detailed subcategories in social dimension. The dimension for cognitive tasks has five categories: elementary clarification (e.g., simply describing the subject matter), in-depth clarification (e.g., identifying assumptions), inferences (e.g., drawing conclusions), judgment (e.g., making value judgments), and application of strategies (e.g., making decisions). These categories are content-free, so that they can be used with different fields of study.

The use of CMC in instructional settings has unlimited potential (Harasim, 1990, 1993; Kuehn, 1994), especially in supporting students' cognitive and metacognitive development. According to Harasim (1990), "there are cognitive benefits to text-based interactions" (p. 48). As compared with speaking, writing provides opportunities for students to reflect and think more deeply about what they are trying to say. This notion is also supported by Vygotsky (1978) who 
indicates the beneficial aspects of writing related to building knowledge. Moreover, Harasim mentions that one of the benefits of text-based on-line discussion is to enhance metacognitive skills through self-reflection. The metacognitive dimension in Henri's model has two areas: metacognitive knowledge and skills. However, the author's previous research study (Hara et al., 2000) found that the category for metacognitive knowledge did not have clear criteria to analyze the data, and the criteria that existed were subjective. The metacognitive knowledge categories in Henri's model are person, task, and strategies. It was easier to distinguish strategies, but it was difficult to separate person and task because people accomplish tasks and students sometimes appear to discuss the people involved as well as tasks at the same time. As a result, Henri's category for metacognitive knowledge was discarded, whereas the category for metacognitive skills was still used in this study. The category of metacognitive skills has five areas: evaluation (e.g., asking whether one's statement is true), planning (e.g., predicting the consequences of an action), self-questioning/regulation (e.g., setting up strategies), self-awareness (e.g., being aware of one's emotion), and reflection (e.g., reflection on personal experiences).

However, using just content analysis has limitations because the outcome of content analysis is the frequency of occurrence for each category. The relationship among different categories is uncertain, and thus the application of FCA to content analysis is considered in order to analyze the data further.

\section{FORMAL CONCEPT ANALYSIS}

Formal Concept Analysis (FCA) is a methodology to analyze qualitative data visually. FCA was first developed by Rudolf Wille in Germany (1982). Even though it has not been popular in the United States, it has become common in Europe. FCA is based on mathematical lattices, and has been applied in many disciplines, such as medicine and psychology, library and information science, software re-engineering, and ecology (see Priss, 1998a). Introduced by Birkhoff in 1940 (Freeman \& White, 1993), the mathematical lattice theory is a branch of finite mathematics. This methodology can be used to analyze and classify survey data and classification.

As an example, Freeman and White (1993) apply FCA to describe social relationships. They indicate the limitation of using traditional graphs to study social networks, although some authors still utilize these graphs in social network analysis (Schweizer, 1997; Stephenson, 1995). Graph theory is an area in discrete mathematics where relationships are illustrated by nodes and lines (e.g., a sociogram). Lattices in FCA are special kinds of graphs that display conceptual hierarchies. Freeman and White suggest the use of lattices because they can represent two-mode network data, whereas the graphs that have been traditionally used in this field represent only one-mode network data. For example, in order to analyze social relationships of people in multiple events (e.g., nine events), 
multiple graphs (e.g., nine graphs) are needed. On the other hand, one lattice can describe the multiple social relationships. Although traditional graphs provide a useful method to represent social interactivity, the present study requires lattices in order to visualize relationships in more than one category.

FCA is based on the notion that a concept consists of two aspects: extension and intension (Ganter \& Wille, 1997). Extension is a set of objects to which a concept refers. Intension is a set of attributes to which a concept refers. FCA originates from a formal context that is defined by three sets: $(G, M, I)$. A formal context consists of a set of formal objects (denoted by $G$ ), a set of formal attributes (denoted by $M$ ), and a relation between the objects and attributes (denoted by $I$ ). A formal context is usually represented by a cross table (or matrix). Therefore, the relationship that the object $g$ has to the attribute $m$ is represented as $g I m$. A formal concept consists of a set of objects (extension) and a set of attributes (intension) so that the attributes which are in the intension are exactly the shared attributes of the objects in the extension and vice versa. With regard to the set of concepts, a conceptual ordering can be defined: a concept is a subconcept of another concept if its extension is contained in the extension of the other concept. With this conceptual ordering, the set of concepts of a formal context forms a mathematical lattice.

FCA is mathematically defined as follows:

For every set of objects $A \subseteq G$ we define the set $A^{\prime}:=\{m \in M \mid g \operatorname{Im}$ for all $g \in A\}$ of all attributes shared by all objects in $A$. Dually the set $B^{\prime}:=\{\mathrm{g} \in \mathrm{G} \mid \mathrm{gIm}$ for all $m \in B\}$ is the set of all objects having all attributes in $B \subseteq M$.

A (formal) concept of the context $(G, M, I)$ is a pair $(A, B)$ with $A \subseteq G, B \subseteq M, A^{\prime}=$ $B$, and $B^{\prime}=A$. The set $A$ is called the extent of the concept, the set $B$ the intent. The hierarchical subconcept-superconcept-relation is formalized by $\left(A_{1}, \mathrm{~B}_{1}\right) \leq\left(A_{2}, \mathrm{~B}_{2}\right)$ : $\Leftrightarrow A_{1} \subseteq A_{2}\left(\Leftrightarrow B_{1} \supseteq B_{2}\right)$ (Stumme, 1995, p. 2).

In order to give an idea of the scope of FCA, an example is provided below related to common films and movies. Table 1 shows the formal context of movies in four categories: rating, type, length, and year of release. Each movie title represents an object (in $G$ ), and four categories of descriptions are attributes (in $M$ ) that distinguish the different objects. To convert the data into a formal context (Table 1), the following are defined: a playing time of less than 100 minutes is short, and more than 100 minutes is long. The year when the movie was released is divided into two categories: before and after 1990.

Figure 1 shows the line diagram of a concept lattice that was computed from the context in Table 1. "An object $g$ has an attribute $m$ if and only if there is an upwards leading path from the circle [node] named by ' $g$ ' to the circle named by ' $m$ '" (Wolff, 1994, p. 431). For example, if we want to watch a movie designated as drama, we have to find a node (concept) labeled as drama in Figure 1. All the nodes below the drama-node are subconcepts, which means that all the movies that are connected from the drama-node below have the attribute of "drama"; that is, 
Table 1. A Context for Movies

\begin{tabular}{|c|c|c|c|c|c|c|c|c|c|c|c|}
\hline \multirow[b]{2}{*}{ Movie } & \multicolumn{4}{|c|}{ Rating } & \multicolumn{3}{|c|}{ Description } & \multicolumn{2}{|c|}{ Length } & \multicolumn{2}{|c|}{ Year } \\
\hline & $\begin{array}{l}P G \\
-13\end{array}$ & $P G$ & $\mathrm{R}$ & $\mathrm{G}$ & Drama & Comedy & Family & Long & Short & $\begin{array}{l}\text { Pre- } \\
1990\end{array}$ & $\begin{array}{l}\text { Post- } \\
1990\end{array}$ \\
\hline The Associate & $x$ & & & & & $x$ & & $\mathrm{x}$ & & & $x$ \\
\hline Emma & & $x$ & & & $x$ & & & $x$ & & & $\mathrm{X}$ \\
\hline $\begin{array}{l}\text { Mississippi } \\
\text { Burning }\end{array}$ & & & & $x$ & $x$ & & & $x$ & & $x$ & \\
\hline Tom \& Huck & & $x$ & & & & & $x$ & & $x$ & & $x$ \\
\hline Multiplicity & $\mathrm{x}$ & & & & & $\mathrm{x}$ & & $x$ & & & $x$ \\
\hline Fargo & & & $x$ & & $x$ & $x$ & & $x$ & & & $x$ \\
\hline $\begin{array}{l}\text { The Secret } \\
\text { Garden }\end{array}$ & & & & $x$ & & & $x$ & $x$ & & $x$ & \\
\hline $\begin{array}{l}\text { Chittychitty } \\
\text { Bang Bang }\end{array}$ & & & & $x$ & & & $x$ & $x$ & & $x$ & \\
\hline
\end{tabular}

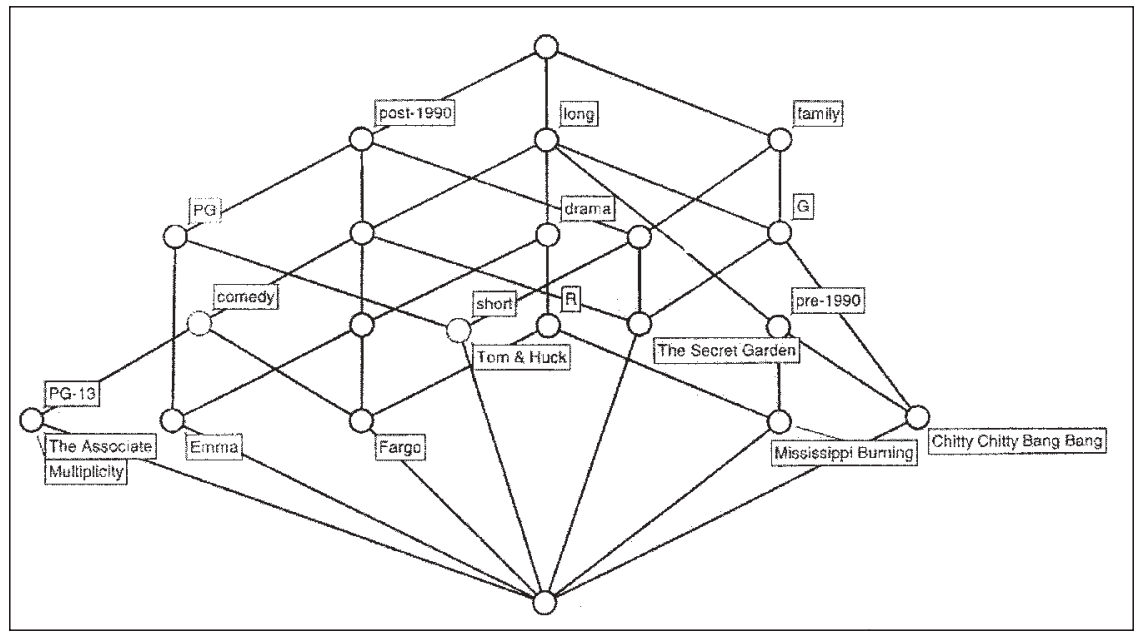

Figure 1. A lattice for the context in Table 1. 
Emma, Mississippi Burning, and Fargo. Additionally, those movies have attributes that are subconcepts of other concepts. For example, the concept where Fargo belongs is a subconcept of these other concepts, so that it has other attributes, e.g., comedy, long, R-rated, and post-1990. Fargo is the only movie that has attributes of drama and comedy at the same time in this context. All short movies (Tom \& Huck) in this example are Family movies; but not all PG movies (Emma and Tom \& Huck) are Family movies.

\section{METHODS}

The study examined on-line discussion of an applied educational psychology class in the spring of 1997. This class used a computer-conferencing system throughout the semester as a supplement to classroom discussion. FCA was used as the main methodology to analyze the on-line discussion after the data were categorized by content analysis.

The original data came from computer conferences which were a part of class activities. FirstClass, asynchronous computer conferencing software, was available for students to access from any computer connected to the university computer network. Originally 22 students were enrolled in this course, but two dropped after the second week. The students consisted of graduate students and a senior undergraduate student. They were required to participate in on-line discussion each week, and their participation was worth 10.5 percent of the final grade. In addition to the weekly participation, students were assigned to be either a "starter" or "wrapper" once a semester. The role of a "starter" was to begin the weekly discussion by asking appropriate questions, whereas the role of a "wrapper" was to summarize the discussion of the week. The computer conference was organized by the same theme as the class, and students were asked to contribute to the weekly discussion based on the required readings.

The data collected for the content analysis process were randomly selected for the following four one-week discussions: Week 2 for Information Processing; Week 4 for Thinking Skills; Week 8 for Mathematics Education; Week 10 for Social Science Education.

Also, it was decided that a unit for data analysis would be a paragraph. ${ }^{1}$ Hence, the identification (ID) number of the raw data for FCA shown in Table 2 represents both a message number and a paragraph number. For example, ID number 1-3 represents the third paragraph of the first message.

\footnotetext{
${ }^{1}$ Because most of the students in this course were graduate students, students tended to have separate paragraphs for different topics. When the researcher saw different ideas in one paragraph, it was considered as two units.
} 
Table 2. Multi-Valued Data After Content Analysis

\begin{tabular}{lccc}
\hline ID \# & Social & Cognitive tasks & Metacognitive skills \\
\hline $1-1$ & Yes & & Self-awareness \\
$1-2$ & No & In-depth clarification & \\
$1-3$ & Yes & Elementary clarification & \\
$1-4$ & Yes & & Reflection \\
$2-1$ & Yes & & \\
$2-2$ & Yes & Judgement & \\
$2-3$ & No & Inferences & Self-questioning \\
$3-1$ & No & Judgement & \\
$4-1$ & No & Application & Evaluation \\
$5-1$ & No & Judgement & \\
\hline
\end{tabular}

\section{Scales}

The original computer conferencing messages were converted by content analysis before applying FCA. The data were already available in the following three categories: social, cognitive tasks, and metacognitive skills. Table 2 shows a part of the data obtained from the previous research project (Hara et al., 2000).

Because the attributes are many-valued in Table 2, they had to be scaled into single-valued attributes in order to compile a lattice. In contrast to a single-valued attribute that either applies or does not apply to an object, a many-valued attribute has different values for different objects. In this example, an attribute can have all five of the following cognitive dimensions: elementary clarification, in-depth clarification, inferences, judgement, and application. In order to apply FCA, the many-valued context (i.e., Table 2) must be converted into a single-valued context (i.e., Table 3), whose attribute values are either 1 or 0 (X-mark or no mark). Furthermore, in this example, it is impossible to place all three categories in one lattice because the lattice becomes too large and complicated to analyze the relationships between concepts. Therefore, the context was divided into two: one context has social and cognitive dimensions and the other context has social and metacognitive dimensions. Table 3, which contains the same data in Table 2, 
Table 3. A Part of Single-Valued Context for Social and Cognitive Dimensions

\begin{tabular}{|c|c|c|c|c|c|c|}
\hline Units & Social & $\begin{array}{l}\text { Elementary } \\
\text { clarification }\end{array}$ & $\begin{array}{l}\text { In-depth } \\
\text { clarification }\end{array}$ & Inferences & Judgement & Application \\
\hline $1-1$ & $x$ & & & & & \\
\hline $1-2$ & & & $x$ & & & \\
\hline $1-3$ & $x$ & $x$ & & & & \\
\hline $1-4$ & $x$ & & & & & \\
\hline $2-1$ & $x$ & & & & $x$ & \\
\hline $2-2$ & $x$ & & & & & \\
\hline $2-3$ & & & & $x$ & & \\
\hline $3-1$ & & & & & $x$ & \\
\hline $4-1$ & & & & & & $x$ \\
\hline $5-1$ & & & & & $x$ & \\
\hline
\end{tabular}

shows a part of the single-valued context for the social and cognitive dimensions. For example, unit 1-3 has a social cue and elementary clarification in Table 2. Thus, unit 1-3 in Table 3 has X-marks under the social and elementary clarification categories.

\section{RESULTS-DIAGRAMS}

Contexts in Formal Concept Analysis can be transformed into mathematical lattices and be graphically represented by line diagrams. The lattice diagrams were drawn using a software called ANACONDA (see Luksch, Skorsky, \& Wille, 1986). Figures 2 to 13 are diagrams analyzed by two combinations of two dimensions concerning the on-line discussions in Weeks 2, 4, 8, and 10: social and cognitive; social and metacognitive.

Figure 2 shows the social and cognitive dimensions for Week 2 . The top node represents the set of all units (objects) as well as the empty set of categories (attributes). In other words, there is no category that applies to all units. The bottom node represents the set of all six categories and the empty set of units. 
Labels above the nodes indicate categories (e.g., social, inference, and application) and those below the nodes indicate the frequencies of units (e.g., 16, 15, and 9). Each node represents a concept that has both categories and units. These nodes are placed into different levels.

In addition to the relationship between concepts, when the diagram is seen horizontally, three levels exist. The top level consists of six concepts from left to right: elementary clarification, social, in-depth clarification, judgement, inferences, and application. The second level consists of three concepts that are combinations of categories: elementary clarification and social applies to one unit; social and judgement applies to one unit; social, inferences, and application applies to one unit. This distinction of levels is not so crucial when data are analyzed by unit. However, it becomes more important when data are analyzed on a person-by-person basis (see the section on social and metacognitive dimensions - individual analysis). In the proceeding sections, social/cognitive dimensions will be discussed first, followed by social/metacognitive.

\section{INTERPRETATIONS}

\section{Social and Cognitive Dimensions}

In order to understand what these diagrams tell us, we have to interpret each diagram. The interpretations will be presented in this section. Figures 2 through 5 represent the relationships between social and cognitive dimensions. The most obvious observation from the diagrams is the frequency of each concept. The frequency of the social dimension decreases from Weeks 2 to 8 (i.e., 19, 18, and 11) respectively, and increases by one to 12 in Week 10. Many students introduced themselves during Week 2, because it was the first week to start the on-line discussion. Consequently, it is natural that Week 2 has more social cues than other weeks. Moreover, Week 10 has only one node (concept) which has cognitive tasks and social cues, whereas Weeks 2, 4, and 8 have more objects belonging to the concepts that have both a cognitive dimension and social cues. This may indicate that the students have become more comfortable with each other, so that the social cues are less embedded in messages and the messages become informal after a few weeks.

The most frequently occurring cognitive tasks are inferences in Week 2 and judgement in Weeks 4, 8, and 10. This inclination is probably caused by the "starter's questions." As mentioned previously, a student was assigned to initiate a weekly discussion. The starter for Week 2 asked questions including five inference questions, three judgement questions, one application, and one elementary question. The starter for Week 8 asked questions including an elementary clarification and a judgement question. This indicates that starters' questions greatly influenced the content of students' discussion. As shown in Figures 3, 4, and 5, Week 8 has the highest frequency in judgement among the three weeks. Ahern et al. (1992) 
VISUALIZING TOOLS / 37

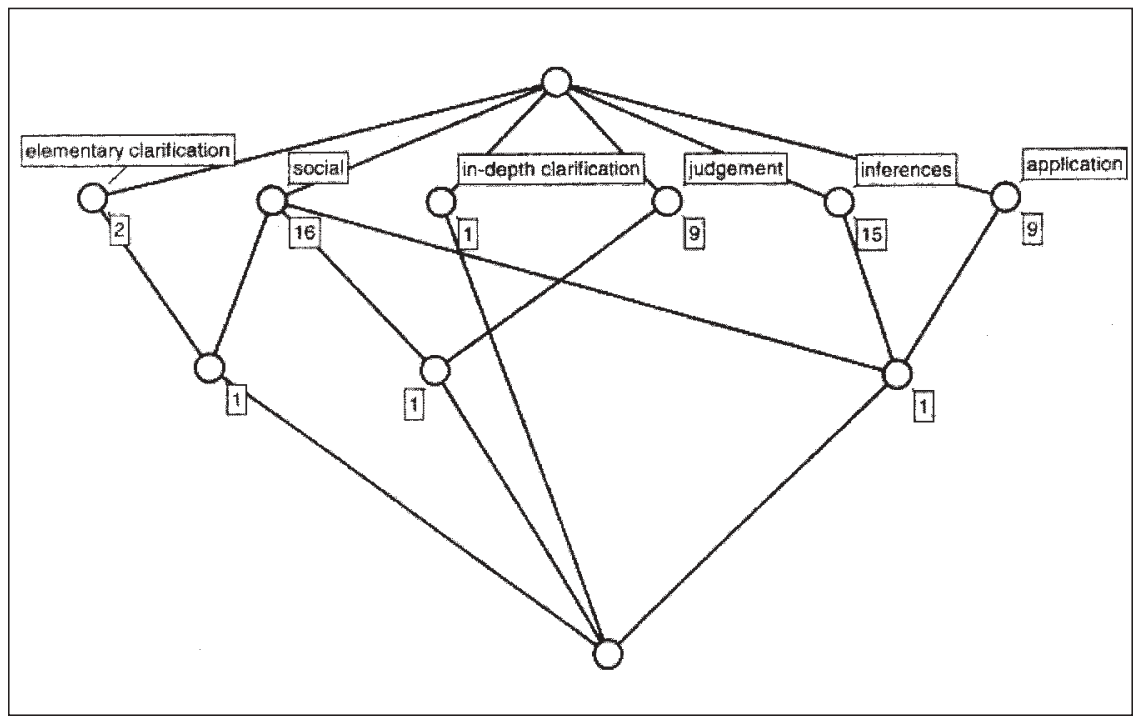

Figure 2. Week 2: Social and cognitive dimensions.

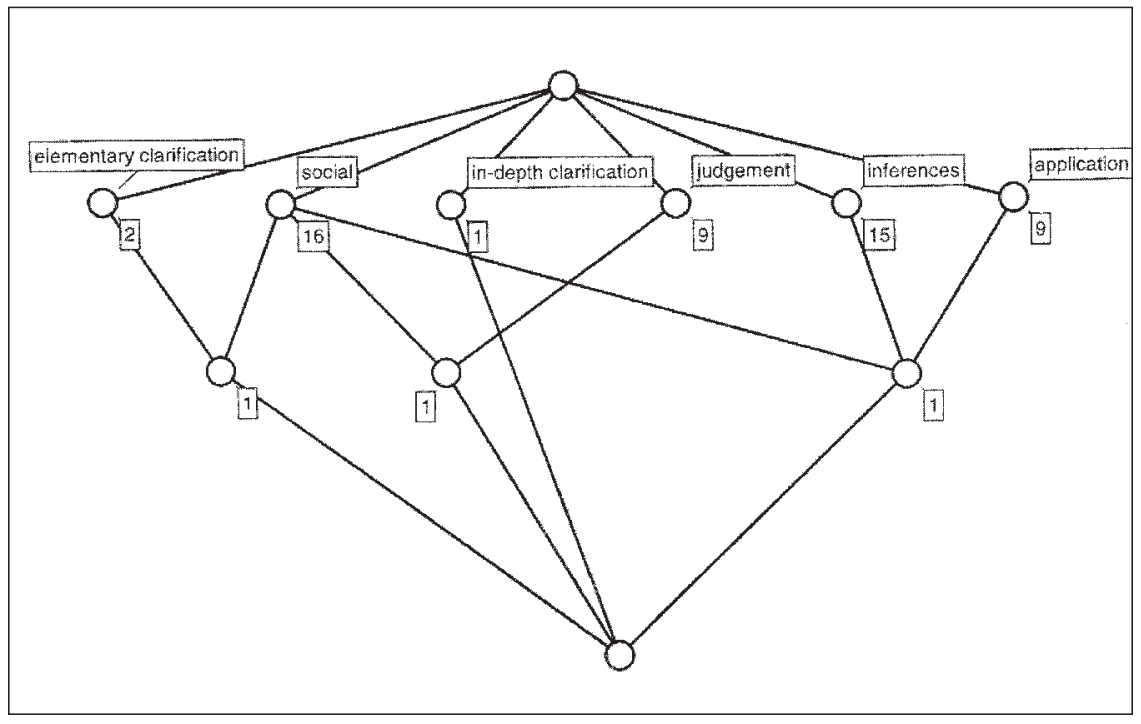

Figure 3. Week 4: Social and cognitive dimensions. 


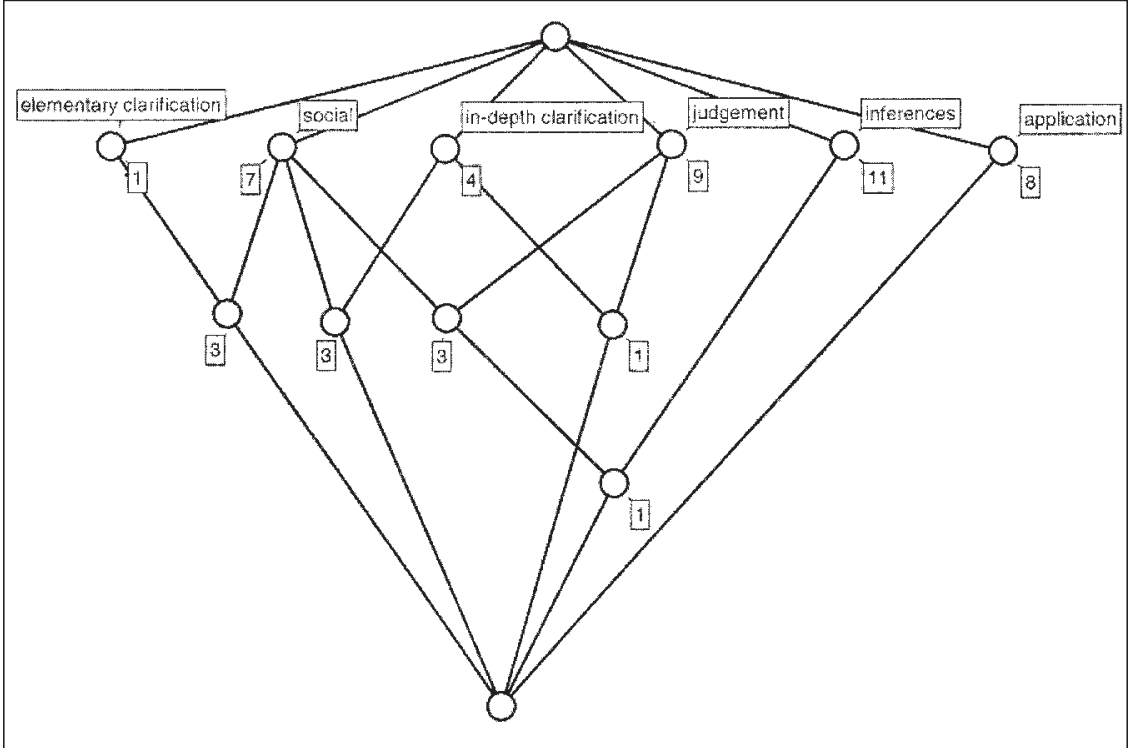

Figure 4. Week 8: Social and cognitive dimensions.

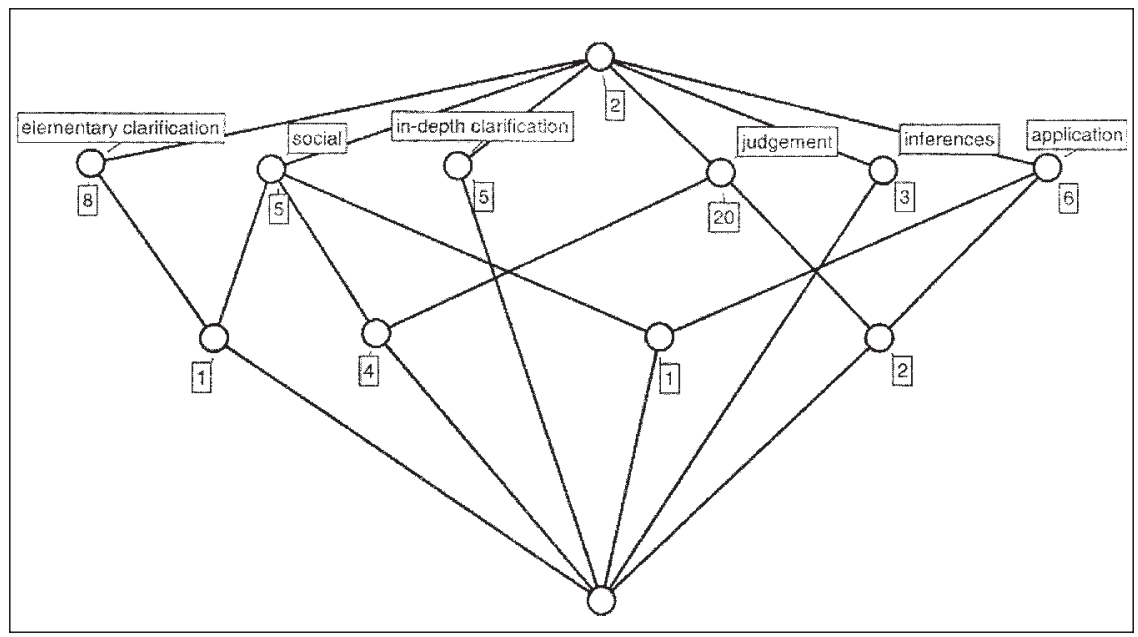

Figure 5. Week 10: Social and cognitive dimensions. 
also found the influence of starter's questions on students' responses. Feenberg (1987) calls these kinds of meta-comments to orient the discussion "weaving," and notes that "weaving comments are essential to giving on-line groups a sense of accomplishment and direction" (p. 180). Thus, it is crucial for students who will initiate discussions to be given precise instructions, so that they can ask proper questions.

Some units have multiple cognitive tasks: inferences/application in Week 2 ; inferences/judgement and judgement/in-depth clarification in Week 4; judgement/application in Weeks 8 and 10. This tendency indicates that some students tend to use lower-level cognitive tasks to achieve higher cognitive tasks, such as using judgement in order to discuss application, as Bloom (1956) claims. Therefore, the content of a unit cannot always be determined to be in one category. Also, these phenomena of units having multiple cognitive tasks can be an indication of the students' abilities to perform complicated cognitive tasks.

\section{Social and Metacognitive Dimensions}

Figures 6 through 9 represent the relationship among social and metacognitive skills. Throughout the four weeks, the most frequently occurring concept in metacognition is reflection. Only in Week 2 does planning become a subconcept of social dimension. In Weeks 4, 8, and 10, all the main concepts appear at the first level. It is interesting to see how students use different metacognitive skills during each of the weeks. Weeks 4 and 10 have only two levels of concepts, whereas Weeks 2 and 8 have three levels. This tendency may indicate that students in Weeks 2 and 8 showed more complicated metacognitive skills than in Weeks 4 and 10 . However, Week 8 has just one unit that is located at level 3. Hence, Week 2 has the most complicated units regarding social and metacognitive dimensions. Additionally, all the weeks except Week 4 have one concept that does not share any units with the social dimension: regulation in Weeks 2 and 8 and reflection in Week 10. In other words, four out of five metacognitive skills are related to the social dimension in Weeks 2, 8, and 10. Some more practical ramifications and interpretations are detailed below.

Henri (1992) questions the possible relationship between social and metacognitive dimensions, although she does not pursue further investigation. These diagrams show that the social dimension plays an important role with metacognition. In Week 2, all the concepts at levels 2 and 3 are subconcepts of the social dimension. In Week 4, all the concepts at level 2 except one (reflection/ self-awareness) are subconcepts of the social dimension. Similarly, in Weeks 8 and 10, all the concepts at levels 2 and 3, except one (regulation/reflection in week 8 ; evaluation/planning in week 10), are subconcepts of the social dimension. This tendency is much clearer in the FCA diagrams analyzed individually (see the social and metacognitive dimensions-individual analysis). 


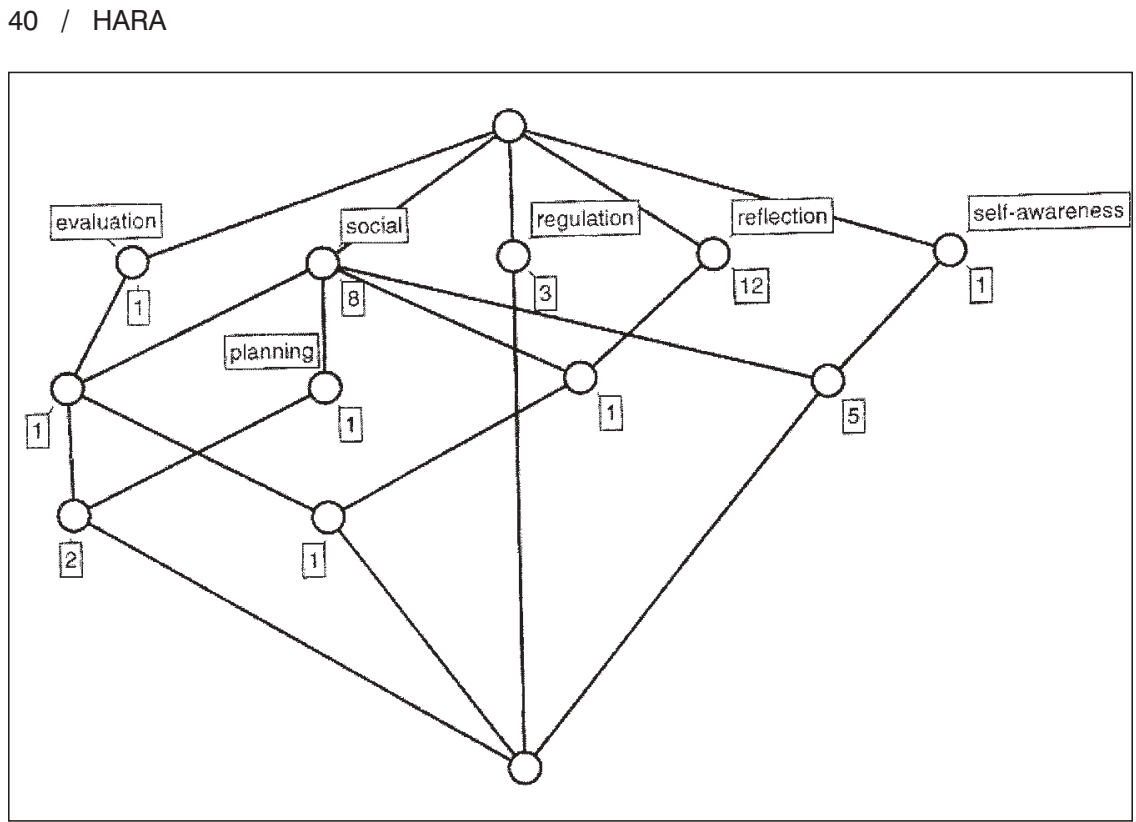

Figure 6. Week 2: Social and metacognitive dimensions.

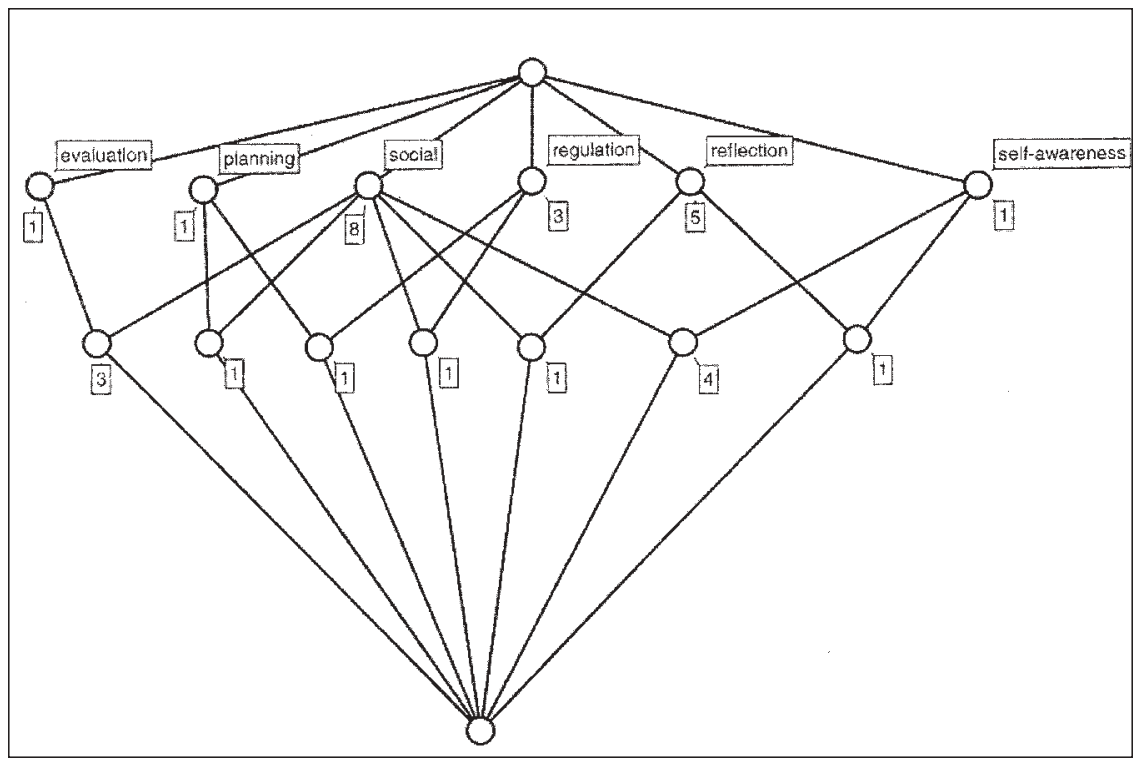

Figure 7. Week 4: Social and metacognitive dimensions. 
VISUALIZING TOOLS / 41

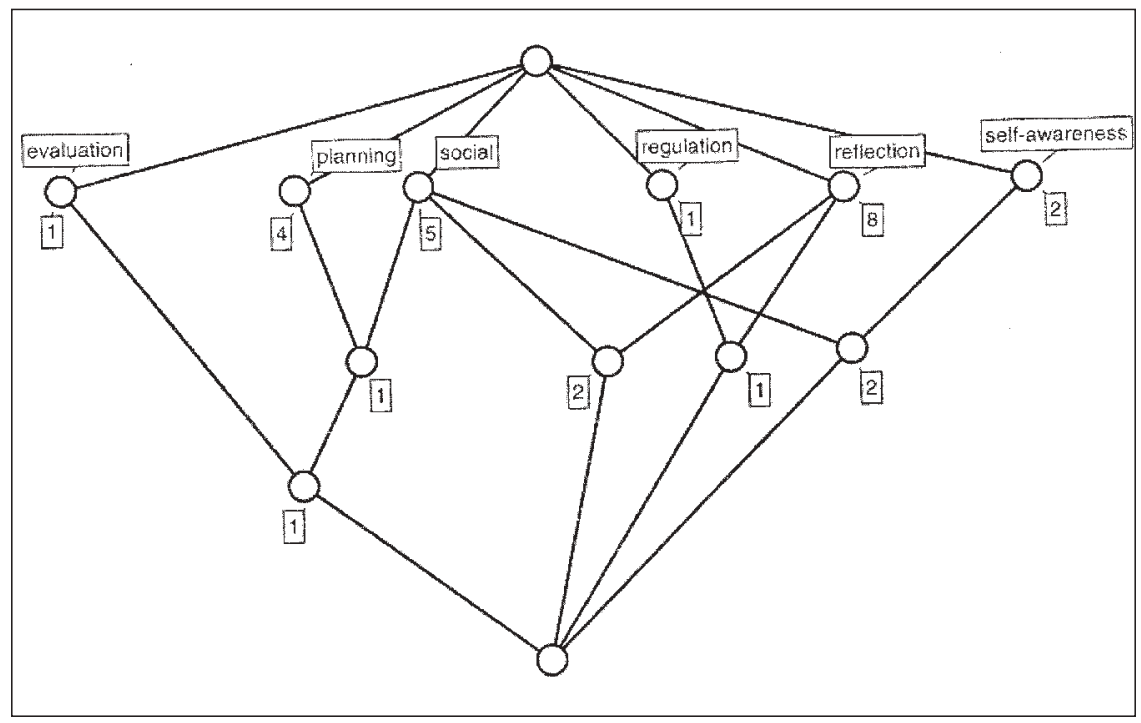

Figure 8. Week 8: Social and metacognitive dimensions.

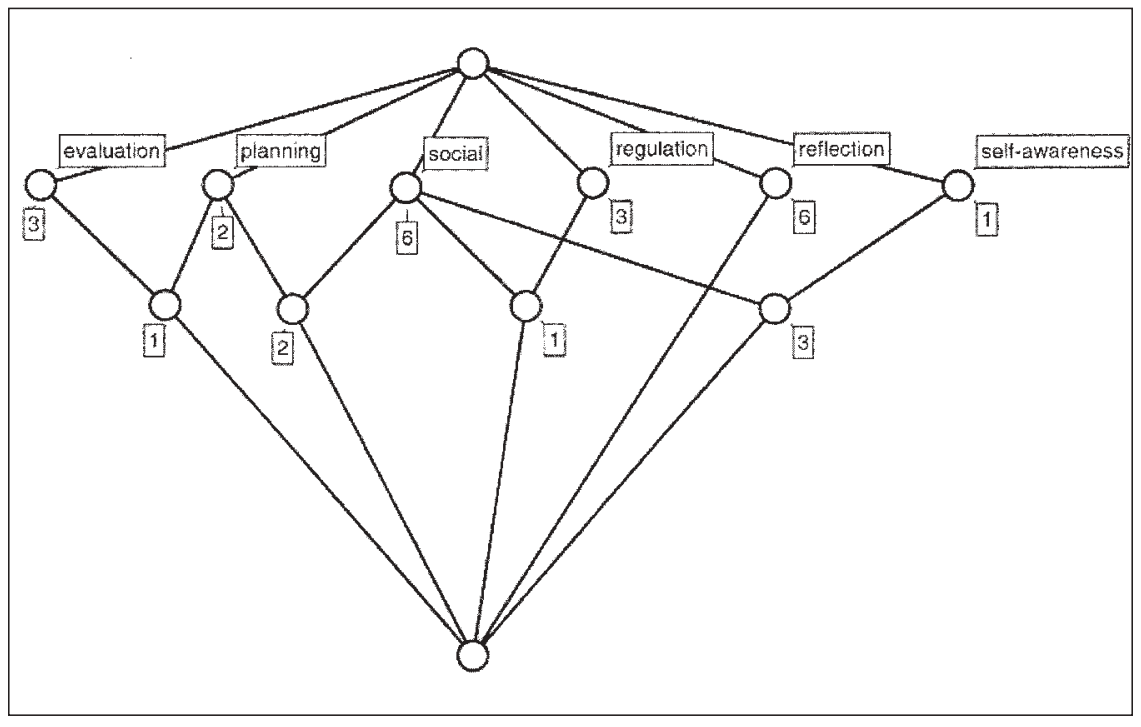

Figure 9. Week 10: Social and metacognitive dimensions. 


\section{Social and Metacognitive Dimensions- Individual Analysis}

In addition to the unit-based analysis with FCA, the social and metacognitive dimensions were analyzed individually (see Figures 10 through 13). This made it easier to see who had what tendencies of social or metacognitive skills. The number attached after a name ${ }^{2}$ represents the sequence of the message. For example, Nancy 1 represents Nancy's first message in a given week. Although each week had a different starter, this analysis proved that the first people who started the discussion (Eliot, Lisa, Greg, and Rich, respectively Weeks 2, 4, 8, and 10) always had attributes of social and self-awareness except Week 8 (Greg). This tendency appears to be natural because starters are opening conversations among the students. Therefore, they were more inclined to use social cues than the other students. In addition, as a starter they might be more aware of how to structure the messages.

Similar patterns were found when a wrapper for each week was analyzed. Wrappers (Amy 2, Irene, and Paul, respectively Weeks 4, 8, and 10) always had attributes of social and regulation. There was no wrapper for Week 2 . The message by Amy 2 had the attributes of planning, social, and regulation. The message by Irene contained the attributes of social, regulation, and self-awareness. The message by Paul had the attributes of social, regulation, and planning. In this conference, a wrapper's role was to summarize the on-line discussions, so that it is natural to have regulation in wrappers' messages. However, if wrappers were required to evaluate discussions in addition to doing a summary, they might have demonstrated deeper metacognitive tasks because evaluation is a higher metacognitive skill than synthesis.

Moreover, level in the diagrams indicates complexity of messages in this case. The lower the message is located in the diagrams, the more elements of social cues or metacognitive skills it holds. When one message involves more than one element, such as a message in level 3 that contains more than one metacognitive skill or social cue, the message is considered as a complex message. For example, the messages composed by Nick throughout Weeks 2, 4, 8, and 10 are located in level 3. This means that Nick consistently wrote complex messages in these weeks. Therefore, by analyzing on-line messages weekly, we might be able to identify which students use more social and metacognitive skills than other students. The study found that some students showed metacognitive skills from the beginning of the semester through Week 10. Similar to Nick, several students wrote consistently complex messages: Lisa in Weeks 2 (level 4) and 10 (level 3); Paul in Weeks 4 and 10 (level 3); Irene in Weeks 2, 4, and 8 (level 3); Amy in Weeks 4 and 8 (level 3). Thus, certain students (e.g., Nick and Irene) in this class

\footnotetext{
${ }^{2}$ The names used here are pseudonyms.
} 
VISUALIZING TOOLS / 43

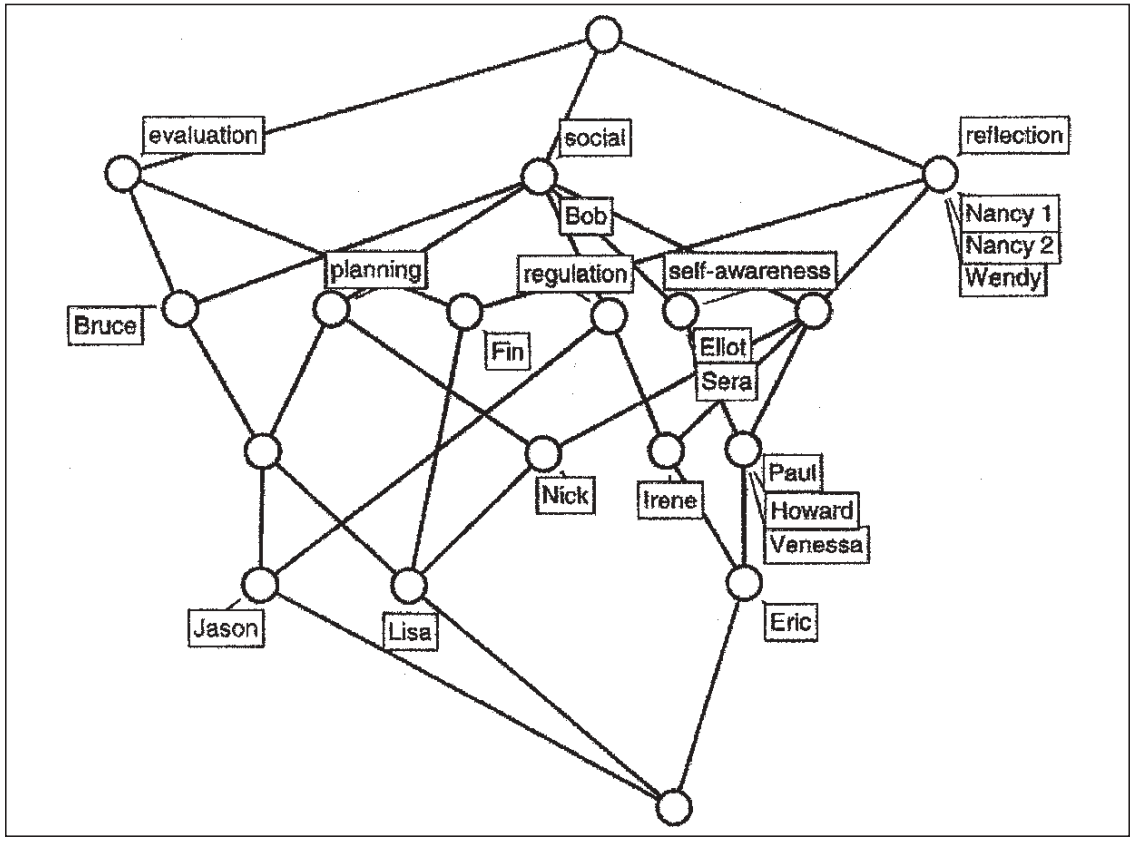

Figure 10. Week 2: Social and metacognitive dimensions.

tended to write more complicated messages, located in level 3 or 4 , than other students.

On the other hand, the study also found that some students showed these skills in their messages during later weeks. For example, Danny did not write a complex message until Week 10, unlike Nick who consistently wrote complex messages. Danny wrote messages in Weeks 4 and 8 under level 2; he did not write any message in Week 2 . However, Danny's message in Week 10 contains social cues and three metacognitive skills (planning, self-awareness, and reflection) in one message, which is one of the most complex messages in Weeks 2, 4,8 , and 10. It is uncertain what made Danny write a complex message in Week 10. Danny might have learned to write a complex message during the weeks prior to Week 10. The present study did not reveal an answer to this question; perhaps Danny learned these metacognitive skills from other students' messages, or became comfortable enough with electronic conferencing to show metacognitive skills in later weeks. Although there are many unknown phenomena that were observed in this electronic conferencing study, we could still see traces of personal tendencies. 
44 / HARA

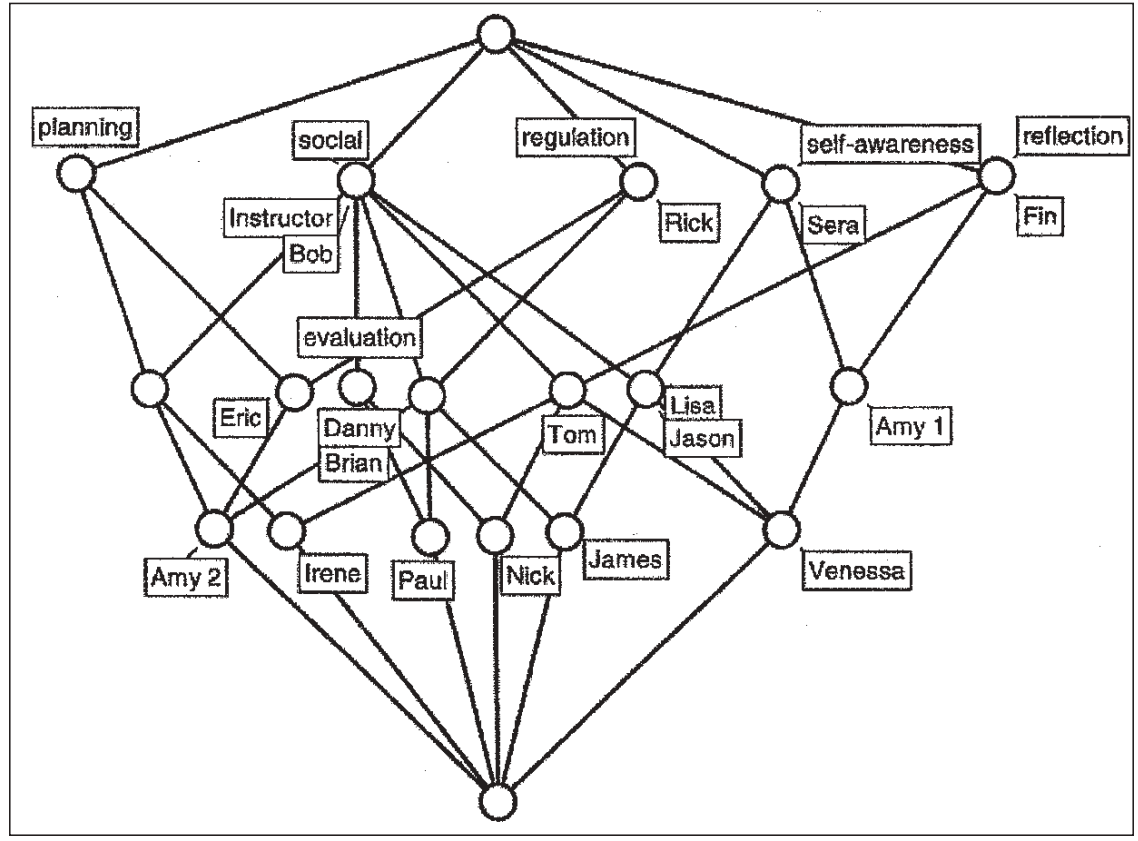

Figure 11. Week 4: Social and metacognitive dimensions.

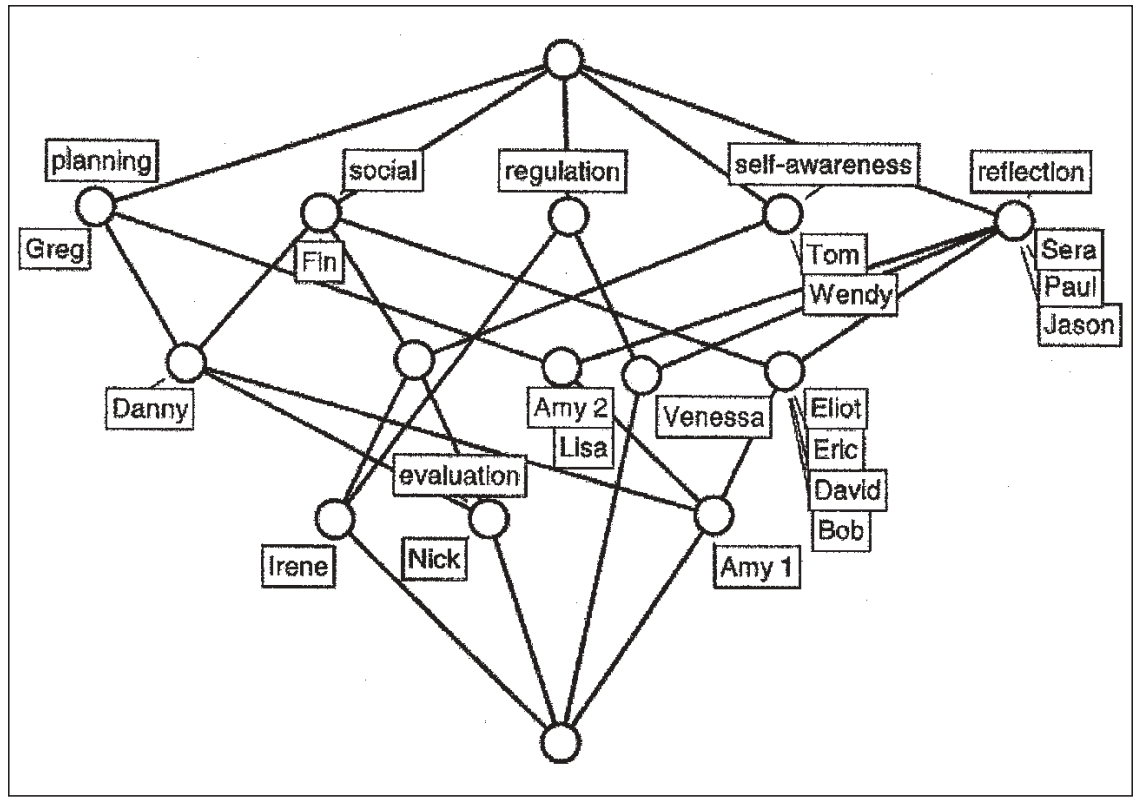

Figure 12. Week 8: Social and metacognitive dimensions. 
VISUALIZING TOOLS / 45

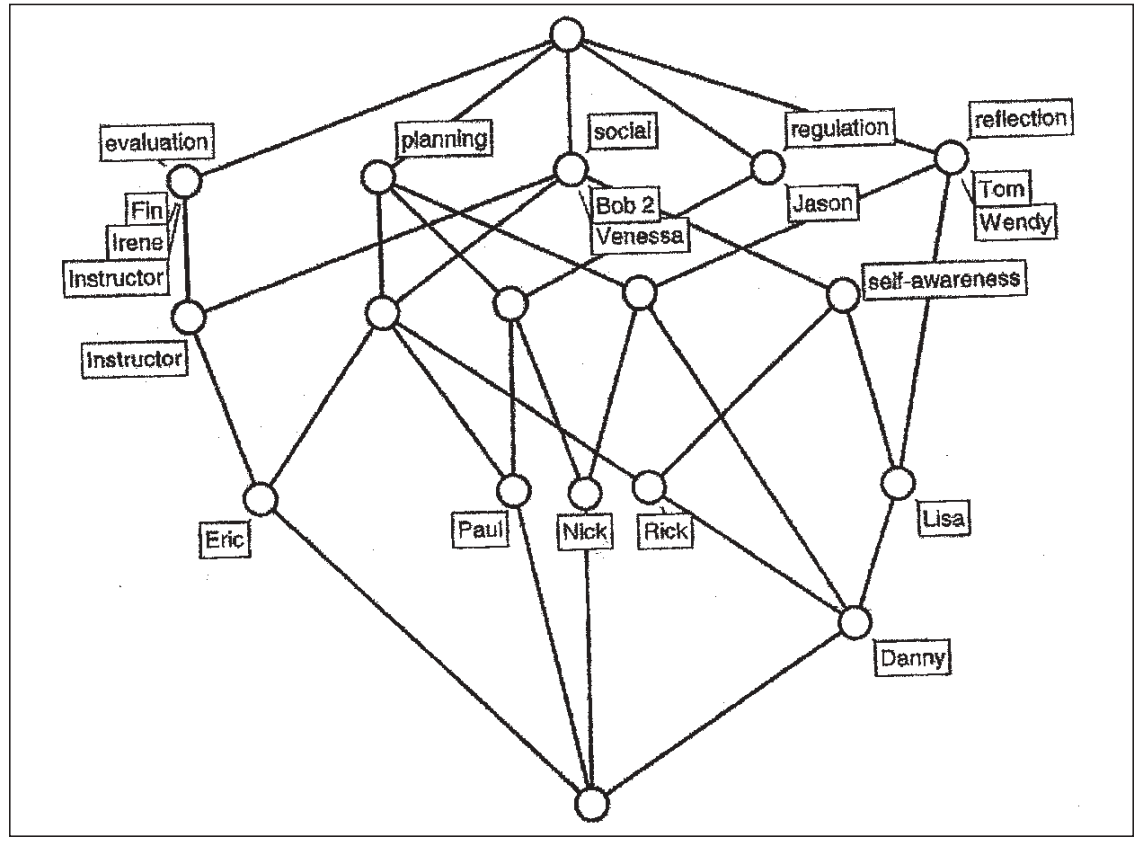

Figure 13. Week 10: Social and metacognitive dimensions.

\section{CONCLUSION}

The present author believes that the combination of content analysis and FCA provides a scientific and systematic way to analyze qualitative data in CMC. This study examines a case study of on-line discussion using FCA. The original data were converted into categories after the content analysis was conducted for the author's previous research project. In this article, the analysis is limited only to the application of FCA. However, different types of analysis, such as Relational Concept Analysis (see Priss, 1998b), can be used for further research. Relational Concept Analysis is "the extension of Formal Concept Analysis - which provides a conceptual hierarchy - to a more general theory that includes other relations among objects, attributes or concepts" (Priss, 1998b, p. 42). Other research (Hara et al., 2000) suggests that the cognitive dimension in Henri's model can be interpreted to contain a learning hierarchy using Bloom's (1956) taxonomy. Therefore, applying Relational Concept Analysis may reveal different relationships among each cognitive dimension. While Relational Concept Analysis is beyond the scope of this article, it may soon be on the agenda for future research on on-line discussions. 
Additionally, as mentioned earlier, FCA could be used to analyze any kind of electronic discussions, such as CSCW in workplaces or CSCL (Computer-Supported Collaborative Learning) in education. Of course, there are many factors of which we are yet uncertain that must surely influence on-line discussions. For example, we are still not clear about what makes a certain group-behavior pattern or personal trait. Without analyzing and evaluating these phenomena, it would be impossible to improve the use of CMC, $\mathrm{CSCW}, \mathrm{CSCL}$, or on-line distance education. The current high demands on distance education (Abbey, 2000; Hara \& Kling, 2000; Loader \& Dutton, 2000) create a need to investigate various tools to analyze online discussions. Incorporating FCA with content analysis will help equip researchers better in investigating the on-line discourses because data visualization provides different perspectives than do traditional methodologies such as examining numerical data.

As we all have seen in other methodologies, FCA has its own limitations. One of the major constraints is that content analysis has to be done before utilizing FCA. This part may seem time-consuming. It is also difficult to interpret the diagrams. It is not intuitive, and thus requires some training. In a similar vein, it is not effective to have too much data in one diagram because it becomes difficult to read. Another shortcoming is a lack of sophistication of the software to generate diagrams. In addition, currently software to analyze data with FCA is available only in Germany (see Darmstadt University of Technology, 2001). Therefore, the development of software could be another research and development opportunity. Despite these limitations, after content analysis is conducted, FCA can represent the data without losing much of the data, unlike statistics, which tends to aggregate data.

In summary, then, this article explores the potential use of FCA to analyze the on-line phenomena as a promising methodological tool, so that using it may stimulate different types of research and reveal new findings. This article introduces a new methodology that sheds light on a different aspect of analyzing on-line discussions. The researcher does not claim that this is the best methodology to analyze data, but rather explanatorily tries a new visualizing methodology and presents the results to the research community. It is important for the field of Computer-Mediated Communication to continuously seek better methodologies to analyze phenomena in electronic environments.

\section{ACKNOWLEDGMENTS}

Curt Bonk, Jennifer Drolet, Uta Priss, and the anonymous reviewers provided helpful insights and comments. 


\section{REFERENCES}

Abbey, B. (2000). Instructional and cognitive impacts of web-based education. Hershey, PA: Idea Group Publishing.

Ahern, T. C., Peck, K., \& Laycock, M. (1992). The effects of teacher discourse in computer-mediated discussion. Educational Computing Research, 8(3), 291-309.

Beatty, B., Bonk, C. J., \& Hara, N. (2001, August). Online interaction: Just how smart are starter-wrapper discussions in the Smart Web? Paper presented at Distance Teaching and Learning 2001, Madison, Wisconsin.

Bloom, B. S. (1956). Taxonomy of educational objectives: Handbook of cognitive domain. New York: McKay.

Bonk, C. J., \& King, K. S. (Eds.) (1988). Electronic collaborators: Learner-centered technologies for literacy, apprenticeship, and discourse. Mahwah, NJ: Erlbaum.

Colomb, G. G., \& Simutis, J. A. (1996). Visible conversation and academic inquiry: CMC in a culturally diverse classroom. In S. C. Herring (Ed.), Computer-mediated communication: Linguistic, social and cross-cultural perspectives (pp. 203-222). Philadelphia, PA: John Benjamins North America.

Darmstadt University of Technology (2001, May 5). AG 1: General Algebra and Discrete Mathematics. Available Online: http://www.mathematik.tu-darmstadt.de/ ags/ag1/Software/software_en.html

Feenberg, A. (1987). Computer conferencing and the humanities. Instructional Science, 16(2), 169-186.

Freeman, L. C., \& White, D. R. (1993). Using Galois lattices to represent network data. In P. V. Marsden (Ed.), Sociological methodology (Vol. 23, pp. 127-146). The American Sociological Association.

Ganter, B., \& Wille, R. (1997). Formal concept analysis: Mathematical foundation. Heidelberg: Springer.

Groeben, N., \& Rustemeyer, R. (1994). On the integration of quantitative and qualitative methodological paradigms. In I. Borg \& P. P. Mohler (Eds.), Trends and perspectives in empirical social research (pp. 308-325). Berlin: W. de Gruyter.

Hara, N., Bonk, C. J., \& Angeli, C. (2000). Content analysis of an on-line discussion in an applied educational psychology course. Instructional Science, 28, 115-152.

Hara, N., \& Kling, R. (2000). Student distress in a Web-based distance education course. Information, Communication \& Society, 3(4), 557-579. [Online]. Available: http://www.slis.indiana.edu/CSI/wp00-01.html

Harasim, L. M. (1987). Teaching and learning on-line: Issues in computer-mediated graduate courses. Canadian Journal of Educational Communication, 16(2), 117-135.

Harasim, L. M. (1990). Online education: An environment for collaboration and intellectual amplification. In L. M. Harasim (Ed.), Online education: Perspectives on a new environment (pp. 39-64). New York: Praeger.

Harasim, L. M. (1993). Networld: Networks as social space. In L. M. Harasim (Ed.), Global networks: Computers and international communication (pp. 15-34). Cambridge, MA: MIT Press.

Henri, F. (1992). Computer conferencing and Content Analysis. In A. R. Kaye (Ed.), Collaborative learning through computer conferencing: The Najaden papers (pp. 115-136). New York: Springer. 
Howell-Richardson, C., \& Mellar, H. (1996). A methodology for the analysis of patterns of participation within computer mediated communication courses. Instructional Science, 24, 47-69.

Kies, J. K., Williges, R. C., \& Rosson, M. B. (1998). Coordinating computer-supported cooperative work: A review of research issues and strategies. Journal of The American Society for Information Science, 49(9), 776-791.

Kuehn, S. A. (1994). Computer-mediated communication in instructional settings: A research agenda. Communication Education, 43, 171-183.

Loader, B. D., \& Dutton, W. H. (Eds.) (2000). Information, Communication \& Society, 3(4).

Luksch, P., Skorsky, M., \& Wille, R. (1986). On drawing concept lattices with a computer. In W. Gaul \& M. Schader (Eds.), Classification as a tool of research (pp. 269-274). North-Holland: Elsevier Science Publishers.

Mason, R., \& Kaye, T. (1990). Toward a new paradigm for distance education. In L. M. Harasim (Ed.), Online education: Perspectives on a new environment (pp. 15-38). New York: Praeger.

Mowrer, D. E. (1996). A content analysis of student/instructor communication via computer conferencing. Higher Education, 32, 217-241.

Newman, D. R., Johnson, C., Webb, B., \& Cochrane, C. (1997). Evaluating the quality of learning in Computer Supported Co-operative Learning. Journal of The American Society for Information Science, 48(6), 484-495.

Priss, U. (1998a). A Formal Concept Analysis Home Page. [On-line]. Available: http://php.indiana.edu/ upriss/fca/fca.html

Priss, U. (1998b). Relational concept analysis: Semantic structures in dictionaries and lexical databases. Shaker Verlag: Aachen.

Romiszowski, A., \& Mason, R. (1996). Computer-mediated communication. In D. Johnassen (Ed.), Handbook of research for educational communications and technology (pp. 438-456). New York: Macmillan.

Schoenfeld, A. H. (1999). Looking toward the 21 st century: Challenges of educational theory and practice. Educational Researcher, 28(7), 4-14.

Schweizer, T. (1997). Embeddedness of ethnographic cases. Current Anthropology, 38(5), 739-759.

Stephenson, K. (1995). The formation and incorporation of virtual entrepreneurial groups. Entrepreneurship: Theory \& Practice, 19(3), 35-53.

Stumme, G. (1995). Exploration tools in Formal Concept Analysis. Preprint 1796, Th-Darmstadt.

Vygotsky, L. S. (1978). Mind in society: The development of higher psychological processes. Cambridge, MA: Harvard University Press.

Weedman, J. (1999). Conversation and community: The potential of electronic conferences for creating intellectual proximity in distributed learning environments. Journal of The American Society for Information Science, 50(10), 907-928.

Wille, R. (1982). Restructuring lattice theory: An approach based on hierarchies of concepts. In I. Rival (Ed.), Ordered sets (pp. 445-470). Dordrecht-Boston: Reidel.

Wolff, K. E. (1994). A first course in Formal Concept Analysis: How to understand line diagrams. In F. Faulbaum (Ed.), SoftStat'93, Advances in statistical software (Vol. 4, pp. 429-438). Stuttgart: Gustav Fischer Verlag. 
VISUALIZING TOOLS / 49

Yates, J., Orlikowski, W. J., \& Okamura, K. (1999). Explicit and implicit structuring of genres: Electronic communication in a Japanese R\&D organization. Organization Science, 10(1), 83-103.

Direct reprint requests to:

Dr. Noriko Hara

School of Library and Information Science

Library 011

10th St. and Jordan Ave.

Indiana University

Bloomington, IN 47405-3907

e-mail: nhara@indiana.edu 